\title{
RELEVANT ISSUES OF RESEARCH OF MINORS' ANTISOCIAL BEHAVIOR
}

\author{
Oleksandra Huzik* \\ Institute of Law, Taras Shevchenko National University of Kyiv, Ukraine, E-mail: \\ oleksandra.guzik@gmail.com
}

(Received: September 2020; Accepted: December 2020; Published: May 2021)

\begin{abstract}
The study of the antisocial behavior of minors is of interest to many scientists: from pedagogues and psychologists to lawyers and criminologists. On the one hand, this has led to important and diverse research detailing the nature, causes, and consequences of deviance among youth. This makes it possible to develop better mechanisms for the prevention of juvenile delinquency, punishment, and resocialization of minor offenders. But on the other hand, this diversity caused contradictory approaches to defining the boundaries of deviance and delinquency, as well as the correlation of these terms. This paper offers an overview of the interdisciplinary scientific discussion on the relationship between delinquency and deviance as types of antisocial behavior, and structures these approaches. It also defines limitations in the field and generates new ideas and directions for future research. In the second part, we examine the causes of juvenile delinquency, with a particular interest in causes that can be corrected. Thus, we found that proper upbringing can "treat" not only anti-social attitudes and values, low educational and professional skills of the offender, poor cognitive and interpersonal skills but also innate tendencies to aggression.
\end{abstract}

Keywords: youth delinquency; juvenile offenders; illegal behavior; antisocial behavior; behavior change.

\section{Introduction}

Societies recognize that investments in youth are an effective way to create safe and prosperous communities. Therefore, the problem of the antisocial behavior of minors and its correction has always been important for the state, and the efforts of educationalists, psychologists, lawyers - aimed to solve this problem.

Antisocial behavior is one of the most complex personality disorders, manifested in violation of the rules of behavior, which is diagnosed as "psychopathic personality" or "sociopathic personality". The term "psychopathy" is used to emphasize that the

\footnotetext{
* Corresponding author: Oleksandra Huzik.E-mail: oleksandra.guzik@gmail.com
} reproduction in any medium, provided the original author and source are credited. 
Huzik, O., (2021)

source of the disorder is internal, based on psychological, biological, or genetic factors, while "sociopathy" is used to emphasize predominant social factors in the disorder: social or family sources of its development and the inability to be social or abide by societal rules. Sociopaths live to satisfy their instinctive needs, ignoring the norms of morality, the requirements of society, so they tend to constantly violate the rules of conduct and laws, despite the possible punishment.

Canadian psychologist J. Godfrey introduces the concept of "abnormal behavior" and defines antisocial personality, which means the inability of the individual to establish strong social relations, unwillingness to adhere to accepted norms, low loyalty to others, unwillingness to abide by their responsibilities to them and lack of guilt for their obscene acts.

Asociality becomes especially noticeable in adolescence. It is expressed in aggression, disorderly sexual behavior, and mechanical views on sex, in the propensity to use alcohol and drugs.

An antisocial person is radically different from other people in their attitude to themselves and others, as well as to the meaning of life. Thus, scientists McKinnon and Micholos indicate: 'an antisocial person views other people as a source of danger or pleasure, without paying attention to their safety, comfort, pleasure. Such a person experiences her impulses as urgent, not relentless, the postponement of the implementation of which or the replacement by something else is unacceptable. At the same time, the satisfaction of these motives leads to debauchery, but not to the feeling of happiness with its inherent sense of self-esteem'.

According to Colman, an antisocial individual tends to avoid responsibility for unacceptable behavior through rationalization and shift the blame onto others. Prolonged communication with such a person always begins to cause dissatisfaction, tension, and irritation.

\section{Delinquency and deviance as types of antisocial behavior of minors}

Antisocial behavior is divided into deviant and delinquent. Deviant behavior - is a system of actions or individual acts of man, which have the character of discrepancy from accepted legal and moral norms in society.

According to Roger JR Levesque's Encyclopedia of Adolescence, the term "deviance" describes characteristics, behavior, or thinking that are significantly different from the behavior of the rest of the population. Therefore, to determine deviance, it is primary to delineate the boundaries of "acceptable" behavior. However, anything beyond these limits is considered a deviation. The deviation can be fixed or variable in both time and content. Deviance is usually determined on the basis of what is not recognized by society as deviant.

18 sciendo Journal of Legal Studies Volume 27 Issue 41/2021 ISSN 2457-9017; Online ISSN 2392-7054. 
Huzik, O., (2021)

In the legal work of Kudryavtsev, the author defines antisocial behavior as behavior in which deviations from social norms are persistently manifested, in the form of selfish, aggressive, and socially passive orientation.

Sociologist William Graham Sumner also has a similar view: according to his definition, deviance is a violation of established contextual, cultural, or social norms, whether folkways, mores or codified law. Therefore, deviance can be as minor as picking one's nose in public or as major as committing murder.

Summarizing the approaches of scientists to the concept of deviance, it should be noted that there is still no single approach to understanding it. The most problematic issue is the definition of the limits of deviance, ie, the violation of which norms should be considered deviant. It also complicates the definition of these limits by the use of evaluative concepts by scientists. For example, according to Roger J. R. Levesque, the deviation from social norms must be "substantial" to fall under the notion of deviance; Kudryavtsev believes that behavioral deviations should be characterized by "stability".

We agree with Neil Joseph Smelzer, a professor of sociology at the University of California, Berkeley (USA), who believes that deviation is difficult to define due to uncertainty and diversity of behavioral expectations. Deviation entails isolation, treatment, correction, or other punishment. Smelzer identifies three main components of deviation: a) a person who has a certain behavior; b) norm or expectation, which is a criterion for assessing behavior as deviant; c) another group or organization that responds to this behavior.

Another type of antisocial behavior along with deviance is delinquency. According to the Encyclopedia of Adolescence, delinquency (from the Latin delinquens - guilt, misdemeanor) is a behavior that refers to the violation of law that, if occurring in an adult, would be considered a crime.

Criminologist Travis Girschi viewed delinquency as acts, the detection of which is thought to result in the punishment of the person committing them by agents of the wider society.

Some psychologists (Orzhekhovskaya, Lysenko, Vynnychuk, Kleiberg, Lychko, etc.) in contrast to lawyers believe that delinquency is a mental readiness to commit a crime. Delinquent behavior refers to minor offenses that are not criminal and, consequently, are not punishable. Delinquency begins with truancy and joining an antisocial group of peers. Then - minor hooliganism, bullying of the younger and weaker, extorting small pocket money from them, stealing bicycles and motorcycles in order to ride. Less common are petty fraud, speculative deals, and defiant behavior in public. According to this approach, the definition of delinquency coincides with antisocial behavior.

Psychologist Kovalev objects to this interpretation of delinquency, pointing out that delinquent behavior is criminal behavior. 
Huzik, O., (2021)

Roger J. R. Levesque also draws attention to this problem, noting that

"the study of deviancy has a long history, as does the focus on adolescents' deviancy. That history has led to important research detailing the nature, causes, and consequences of deviancy among youth and has led to important developments in the study of deviance itself, but this lines of research are not without their limitations. Perhaps the strongest limitation in this area of research is the lack of focus on discerning what constitutes deviancy. As a result, measures tend to focus on behaviors and the focus on deviant behaviors varies considerably. Some (ie Donovan) adopt a general approach that is synonymous with problem behavior, as assessed by the frequency of involvement in nine problem behaviors (e.g., lying, cheating, stealing, and aggression) during a certain time period, typically within the past 6 month or year. Other (Kamphaus, R. W., Huberty, C. J., DiStefano and others) approaches simply index conduct problems, such as questions that would be answered by teachers who rate youth on their tendency to engage in antisocial and rule-breaking behavior, including destroying property. Researchers tend to borrow measures from projects that were not aimed at understanding deviance but at exploring, for example, delinquency. When coupled with differences in who rates youth (self-reports, teacher or parent reports, or investigator observations), what constitutes deviancy becomes even more important to consider."

Summarizing the approaches to the definition of deviance and delinquency as types of antisocial behavior, we can conclude that deviance is a behavior that contravenes the norms that govern social relations. This issue is problematic due to the different approaches of scientists to delineate the boundaries of deviance.

We cannot agree with the broader approach to the concept of deviance, according to which violations of any norms are included in this concept, as the violation of the legal norms is covered by the concept of delinquency. The distinction between these two, in our opinion, is appropriate for further theoretical research and practice, as delinquent behavior has significant features. In particular, delinquency, in contrast to deviance, always has socially dangerous consequences, causes changes in the perception of the offender by society, leads to the realization of the juvenile himself as a criminal, and, consequently, opposition to the society that rejects him. These features necessitate a more detailed study of the causes and consequences of delinquent behavior, prospects, and risks for juvenile offenders to determine effective ways to correct their behavior and further resocialization, which will be discussed in the next section.

\section{Psychological aspects of causes of minors` delinquent behavior}

Delinquent behavior has a complex nature due to a variety of factors that are in complex interaction. Many reasons that cause delinquent behavior in adolescents,

20 sciendo Journal of Legal Studies Volume 27 Issue 41/2021 
Huzik, O., (2021)

"Vasile Goldiş" Western University of Arad

Relevant Issues of Research of Minors' Antisocial Behavior

experts are able to identify and eliminate it in a timely manner. However, a number of factors have not yet been found effective. To some extent, this category includes factors of psychological and pedagogical nature.

Researcher Zaichenko classifies risk factors for delinquent behavior of minors by areas into the following groups:

a) socio-economic - lower living standards, property stratification of society, limiting opportunities for socially acceptable ways of earning, unemployment, easily accessible alcohol, and tobacco;

b) socio-pedagogical - the crisis of the family, the growing number of families with conflict and antisocial upbringing, problems related to learning, conflicts with teachers, low social status of adolescents in the student body, poor system of apart from school activities for children and youth;

c) socio-cultural - lowering the moral and ethical level of the population, spreading criminal subculture, destruction of spiritual values, increasing the number of informal youth associations, which are dominated by the cult of power, media promotion of anti-social stereotypes of behavior;

d) psychological - character accentuations, emancipation reaction, grouping reaction, desire for self-affirmation, satisfaction of curiosity, desire to look like an adult, the need to change the mental state in a stressful situation, infantilism, increased anxiety;

e) biological - disorders of the enzymatic and hormonal systems of the body, congenital psychopathy, minimal brain dysfunction due to organic damage to the brain, the effects of heredity, the impact of the natural environment.

Conflict theory emphasizes that social patterns of behavior are rejected if they are based on the norms of another culture. For example, a criminal is considered to be the bearer of a certain subculture that conflicts with the prevailing type of culture in society. According to socio-critical theory, crime stems from a system of social inequality that holds power at the top and those without power at the bottom. As a result, different social groups have completely different opportunities for meeting the same needs.

It has been found that many of the social and economic factors play a role in youth involvement in crime and delinquency. A range of individual, family, and community-level factors either put youth at risk of delinquent behavior or act as protective factors to inhibit that behavior. Various factors are identified potentially influencing individuals' paths to criminality, such as school attachment and aspirations, parental supervision, discipline, abuse or neglect, and delinquent peer groups, as well as neighborhood factors related to low-income, crowded households, and residential mobility.

A number of studies (Glueck and Glueck, Nye, Hirschi, Greenberger and Steinberg, McMorris and Uggen; Staff and Uggen) have focused on establishing a link between

Sciendo Journal of Legal Studies Volume 27 Issue 41/2021 
Huzik, O., (2021)

early employment of minors and their delinquent behavior. Studies have shown that working adolescents have a much higher risk of delinquency and commit crimes a crime of greater gravity than those who do not work. Also, among high school students, those who worked intensively consumed alcohol and drugs more often than those who remained unemployed. However, the results of these studies were later criticized, given the lack of causal links between the employment of a minor and the commission of further offenses. It is assumed that adolescents with pre-existing antisocial behavior were engaged in intensive work and that employment could also be the result of problems in family relationships, as a result of which the minor later committed an offense.

In finding out the causes of adolescents' violation of norms and rules of behavior, scientists turn to the analysis of the psychological climate of the family, the emotional psychological relationships of adolescents with peers and adults.

Psychologists (Asanova, Mozhiginsky) have shown that physical, psychological, or sexual abuse of children increases their risk of suicidal behavior and crime. Most often, the psychological trauma of childhood is associated with the fact that there were alcoholics or drug addicts in the family, or there was violence in various forms. These traumas later become a source of aggressive actions: crimes, school violence, domestic violence against a sentimental partner, insults and humiliation of peers, use of weapons, and suicide attempts.

Peer influence has a significant impact on juvenile delinquency. Studies presenting participants with situations involving pressure to engage in antisocial conduct have found that peer influence increases between childhood and mid-adolescence and declines slowly during the late adolescent years. The influence of peers can act directly when the adolescent responds to the pressure of others, and in particular through the desire for the approval of peers and fear of rejection. Peer approval is especially important in group situations, and it is not surprising that minors are much more likely to be offended in groups than adults. It has been empirically established that adolescents are more likely to take risks in the presence of peers than when they are alone or with an adult, and that this "peer effect" does not occur in adults.

An important component of socialization in childhood and adolescence is awareness of the importance of gender. This includes studying how society in our world sees femininity and masculinity, as well as behavioral expectations related to gender. Girls are more likely to be encouraged to be pleasant, friendly, selfless, attractive, and addictive. Being a man is usually equated with competitiveness, independence, rationality, and strength, which is why boys are more prone to violent crimes and delinquent behavior.

22 S sciendo Journal of Legal Studies Volume 27 Issue 41/2021 ISSN 2457-9017; Online ISSN 2392-7054. 
Huzik, O., (2021)

\section{Conclusions}

Regarding the biological preconditions of delinquent behavior, a group of British scientists has shown that antisocial behavior of adolescents is not necessarily the result of poor upbringing or bad peer influence. It can be caused by a malfunctioning child's brain. The researchers scanned the brains of several adolescents with varying degrees of behavioral disorders. During the scan, they were shown photos depicting angry or sad faces. At the same time in normal children, the sites of a brain responsible for emotions noticeably became more active. In "difficult" adolescents, this reaction was much weaker. The researchers concluded that these children felt worse about the grief of others, resulting in antisocial behavior.

At the same time, geneticists have proven that the gene responsible for aggression is "treated" by proper upbringing. Maternal care, good upbringing, and sufficient physical activity can overcome the action of a "bad" gene responsible for aggression and antisocial behavior. This conclusion was reached by the American scientist Stephen Suomi, as a result of an experiment on monkeys. At a press conference in London, he stated that his work fully confirms the conclusions made in 2002 co-led by Terrie Moffitt of the Institute of Psychiatry at King's College London. She and her colleagues have been following the fate of 1,037 children born in 1972 in New Zealand for 26 years. The researchers suggested that these children were more likely to grow up aggressive because they inherited a "short" version of a gene called MAOA (aggression gene). But only adolescents deprived of parental care and upbringing embarked on the antisocial path - all the others grew up completely normal people.

Thus, adolescence is a difficult period of mental development. Antisocial behavior of minors is due to a number of factors of the external social environment (especially the microenvironment) and internal self-understanding and individual response to various life difficulties. If the concepts of gender, physiological characteristics, and the status of the adolescent's family cannot be changed, then the psychological preconditions of delinquency can be adjusted with the help of pedagogical methods, in particular, by applying them through the institution of probation with appropriate services.

\section{Acknowledgments}

The author thanks the anonymous reviewers and editor for their valuable contribution.

\section{Funding}

This research received no specific grant from any funding agency in the public, commercial, or not - for - profit sectors. 
Huzik, O., (2021)

\section{Author Contributions}

The entire article was written by Oleksandra Huzik.

\section{Disclosure Statement}

The author has not any competing financial, professional, or personal interests from other parties.

\section{References}

1. Asanova, N. (1997). Child abuse: basic methodological issues, practical and legal aspects. Guide to preventing violence against children. $\mathrm{M}$.: VLADOS.

2. Berndt, T. (1979) Developmental Changes in conformity to Peers and Parents, 15 DEV. PSYCHOL. 608, 608-616

3. Block, J. H. (1984). Sex-role identity and ego development. San Francisco: Jossey-Bass.

4. Burke, P.J. (1989). Gender identity, sex, and school performance. Social Psychological Quarterly, 44, 83-92.

5. Coghlan, A. (2004, July 19). Good mothers stop monkeys going bad. Retrieved September 15, 2020, from https://www.newscientist.com/article/dn6177-good-mothersstop-monkeys-going-bad/

6. Donovan, J.E., Jessor, R., Costa, F.M. (1991). Adolescent health behavior and conventionality-unconventionality: An extension of problem behavior theory. Health Psychology, 10, 52-61. MedGoogle Scholar.

7. Ewbank, M., Passamonti L., Hagan C., Goodyer I., Calder A., Fairchild G. (2018) Psychopathic traits influence amygdala-anterior cingulate cortex connectivity during facial emotion processing. Social Cognitive and Affective Neuroscience, DOI: 10.1093/scan/nsy019

8. Glueck, S., Glueck, E. T. (1951). Unraveling juvenile delinquency. Cambridge, Mass: Published for the Commonwealth Fund by Harvard University Press.

9. Godfrey, J. (1992). What is psychology / J. Godfrey. - M.

10. Golovin, S. (2001). Dictionary of a practicing psychologist. Comp.. - 2nd ed., Rev. and add. - Mn.: Harvest, M.: AST.

11. Greenberger, E., Steinberg, L. (1986). When teenagers work: The psychological and social costs adolescent employment. New York: Basic Books.

12. Guyer, A., McClure-Tone, E., Shiffrin, N., Pine D., Nelson, E. (2009). Probing the Neural Correlates of Anticipated Peer Evaluation in Adolescence. CHILD DEV. 1000, 1000-15.

13. Hare, R. D. (1999). Without conscience: The disturbing world of the psychopaths among us. London: The Guilford Press.

14. Hiraschi, T. (1969). Causes of Delinquency, Berkeley: University of California Press. 15. Jackman, M. R. (1994). The velvet glove: Paternalism and conflict in gender, class and race relations. Berkeley: University of California.

16. Kamphaus, R. W., Huberty, C. J., DiStefano, C., Petosky, M. D. (1997). A typology of teacher-rated child behavior for a national U.S. Sample. Journal of Abnormal Child Psychology, 25, 453-463.PubMedGoogle Scholar.

17. Kleiberg, Y. (2001). Psychology of deviant behavior: textbook. manual for universities

24 Sournal of Legal Studies Volume 27 Issue 41/2021

ISSN 2457-9017; Online ISSN 2392-7054

Web: publicatii.uvvg.ro/index.php/jls. Pages $17-25$ 
Huzik, O., (2021)

Relevant Issues of Research of Minors' Antisocial Behavior

18. Kochyunas, R. (2004). Psychological counseling. Group psychotherapy M.: "Academic project".

19. Kovalev, V. (1970) Psychology of personality. - Ed. M .: Enlightenment.

20. Kudryavtsev, V. (1982). The legal behavior: norm and pathology. Kudryavtsev. - M.

21. Levesque, R.J.R. (2011). Deviancy. In: Levesque R.J.R. (eds) Encyclopedia of Adolescence. Springer, New York, NY.

22. Lichko, A. (1991). Psychopathies and character accentuations of adolescents. A.E. Person.

23. Lysenko, I. (2013). Study of the peculiarities of manifestation deviant (delinquent) behavior of the adolescent. Problems of Modern Psychology, 20. Retrieved from http://vkhsac.in.ua/index.php/2227-6246/article/viewFile/159751/158991

24. McMorris, B.J., Uggen, C. (2000). Alcohol and employment in the transition to adulthood. Journal of Health and Social Behavior, 41, 276-294.

25. Monahan, K., Steinberg, L., Cauffman E. (2009). Affiliation with Antisocial Peers, Susceptibility to Peer Influence, and Desistance from Antisocial Behavior During the Transition to Adulthood. 45 DEV. PSYCHOL. 1520, 1520-30.

26. Mozhginsky, Y. (2009). Approaches to the analysis of severe forms of antisocial behavior in children and adolescents. Legal psychology, 1.

27. Mukhina, V. (2002). Development psychology: phenomenology of development, childhood, adolescence: Uch. for stud. Universities. M.: Ed. Center "Academy".

28. Nye, F.I. (1975). Family relationships and delinquent behavior. Westport, CT: Greenwood Press.

29. Orzhekhovskaya, V. (1996). Prevention of offenses among minors: textbook. Orzhekhovskaya. - K.

30. Sedykh, K. (2015). Delinquent teenager: a textbook on psychoprophylaxis, diagnosis, and correction of illegal behavior of adolescents for students of psychological, pedagogical, social, legal specialties and interns-psychiatrists. Kyiv: Slovo Publishing House.

31. Staff, J., Uggen, C. (2003). The fruits of good work: Early work experiences and adolescent deviance. Journal of Research in Crime and Delinquency, 40, 263-290.

32. Sumner, W.G. (1955). Folkways. New York, NY: Dover.

33. Vinichuk, N. (2004). Psychology of anomalous behavior Retrieved from http://www.twirpx.com/file/130534.

34. Vyain, S., Scaramuzzo, G., Cody-Rydzewski, S., Griffiths, H., Strayer, E., Keirns, N., Little, W. (2014, November 06). Chapter 7. Deviance, Crime, and Social Control. Retrieved September 20, 2020, from https://opentextbc.ca/introductiontosociology/chapter/chapter7deviance-crime-and-social-control/

35. Zaichenko, M. (2010). Diagnosis and correction of deviant behavior of students. Social pedagogy, 2, 41-55.

36. Zimring, F., Laqueur H., (2015). Kids, Groups, and Crime: In Defense of Conventional Wisdom 52 J. RES. CRIME DELINQ. 403, 403-413. 